\title{
Effects of nicotine on the resistance to extinction of a jump-up avoidance response in rats
}

\author{
MICHEL TREMBLAY and MORRIE BAUM \\ Université de Moncton, Moncton, New Brunswick, Canada
}

(Morris Moscovitch, sponsor)

\begin{abstract}
Seventy-five rats were trained to avoid footshock in the Baum jump-up apparatus. Subsequent to training, the rats were injected with one of five different doses of nicotine, and the rats' persistence in responding was observed with the shocker disconnected (extinction). Only the high dose of nicotine $(.8 \mathrm{mg} / \mathrm{kg})$ had a significant effect on resistance to extinction, eliminating most responding and appearing to be physically debilitating. Intermediate doses $(.05-.4 \mathrm{mg} / \mathrm{kg}) \mathrm{had}$ a nonsignificant tendency to increase extinction responding. These results are contrasted with results obtained in a similar paradigm using other drugs.
\end{abstract}

Baum (1965) developed an automated ledge box for the avoidance training of rats. In the box, the rats' avoidance responses were characterized by rapid acquisition and a fair amount of resistance to extinction. The resistance to extinction of the response in this apparatus has proven useful in studies of various pharmacological agents, when a drug is administered following acquisition and prior to extinction. Baum (1969) found that ethanol administered in this way prolonged rats' responding in extinction. Similar effects were found with hashish resin (Jaffe \& Baum, 1971) and chlordiazepoxide or diazepam (Ziskind, Amit, \& Baum, 1974). However, ACTH was found to have no significant effect on avoidance extinction (Ziskind, Baum, \& Amit, 1973). In this study, we explored the effects of various doses of nicotine on resistance to extinction of avoidance using the procedure of the previously mentioned studies.

\section{METHOD}

The subjects were 75 experimentally-naive female hooded rats obtained from the Canadian Breeding Laboratory, St. Constant, Quebec. They were housed two per cage, had food and water always available, and weighed 160 to $210 \mathrm{~g}$ at the time of testing. The automated apparatus, the same as that used in the studies mentioned previously, consisted of a large, cube-shaped box fitted with an electrifiable grid floor and a retractable ledge (see Baum, 1965, or Baum. in press, for a pictorial representation of the apparatus). Shock intensity in acquisition was consistently $0.5 \mathrm{~mA}$ and was generated by a Grason-Stadler scrambled shock source.

All subjects were trained with a standard procedure, differing only in the dose of nicotine injected immediately following completion of avoidance acquisition. The nicotine was $98 \%$ pure and contained 1.005

This paper is based on a master's thesis by Michel Tremblay. Research funding was provided by grants to Morrie Baum from the National Research Council of Canada, and from the Conseil de Recherche, Université de Moncton. M. Tremblay's mailing address is: 1612 des Grands Ducs, Chicoutimi, Quebec, Canada G7H 5T1. M. Baum's mailing address is: 1570 Lawrence Avenue West, Suite 205, Toronto, Ontario, Canada M6L 1C2. to $1.015 \mathrm{~g}$ of drug per cubic centimeter of water with a refractory index between 1.527 and 1.529. It was obtained from BDH Chemicals Ltd., Poole, England, via their Montreal Office. The nicotine was appropriately diluted, hermetically sealed, and stored in a dark place at room temperature between experimental sessions. The drug was administered via intraperitoneal injection using an insulin syringe.

Acquisition of avoidance began when the naive rat was placed on the grid floor. After $10 \mathrm{sec}$, shock began and continued until the rat escaped to the ledge. The rat remained on the ledge for $30 \mathrm{sec}$, then the ledge retracted, dropping the rat back onto the grid. As soon as the ledge was fully retracted, it returned to the box, setting up the next trial. The subject could avoid shock by climbing to the ledge within $10 \mathrm{sec}$; otherwise the rat was shocked until it escaped to the ledge. Trials continued until the rat achieved an acquisition criterion of 10 consecutive avoidance responses.

Subsequent to the tenth consecutive avoidance response, the shock source was disconnected and the subject was immediately removed from the apparatus and injected with one of five doses of nicotine-placebo (distilled water): $.05, .2, .4$, or $.8 \mathrm{mg} / \mathrm{kg}$. After being injected, the subject was placed in a nearby covered plastic pail for a $15-\mathrm{min}$ waiting period, after which extinction trials were run. With the shocker disconnected, the extinction trials began with an intertrial interval (i.e., the subject was returned to the apparatus and placed on the safety ledge). Extinction trials continued until the rat achieved an extinction criterion of five consecutive minutes on the grid floor without climbing to the ledge, or until 200 trials occurred.

\section{RESULTS}

The results, summarized in Table 1, were analyzed by means of a Kruskal-Wallis one-way analysis of variance by ranks. The five groups were similar in acquisition as measured by (1) number of trials to acquisition criterion, and (2) number of escape trials or shocks received (Hs $=2.60$ and 2.62 , n.s.). The groups differed on two extinction measures, however: the latency of the first extinction response $(\mathrm{H}=22.75, \mathrm{p}<.001)$ and the number of responses made in extinction $(\mathrm{H}=21.27, \mathrm{p}<$ .001). In comparing two groups at a time by means of two-tailed Mann-Whitney U tests, the group administered $.8 \mathrm{mg} / \mathrm{kg}$ differed from other groups on these extinction measures (US $<35$, ps $<.002$, but there were no sig- 
Table 1

Summary of the Results

\begin{tabular}{|c|c|c|c|c|c|c|}
\hline & \multicolumn{6}{|c|}{ Nicotine Dosage $(\mathrm{mg} / \mathrm{kg})$} \\
\hline & Placebo* & $0.05^{*}$ & $0.2 *$ & $0.4^{*}$ & $0.8^{*}$ & $\mathrm{p}^{* *}$ \\
\hline $\begin{array}{l}\text { Median number of trials to } \\
\text { criterion in acquisition }\end{array}$ & 16.0 & 17.0 & 15.0 & 14.0 & 16.0 & n.s. \\
\hline $\begin{array}{l}\text { Median number of shocks received } \\
\text { (escape trials) in acquisition }\end{array}$ & 4.0 & 4.0 & 4.0 & 4.0 & 5.0 & n.s. \\
\hline $\begin{array}{l}\text { Median latency of the first } \\
\text { response in extinction }(\mathrm{sec})\end{array}$ & 3.4 & 2.8 & 8.8 & 4.0 & 300.0 & $<.001$ \\
\hline $\begin{array}{l}\text { Median number of responses } \\
\text { in extinction }\end{array}$ & 37.0 & 56.0 & 52.0 & 96.0 & 0.0 & $<.001$ \\
\hline $\begin{array}{l}\text { Mean number of responses in } \\
200 \text { extinction trials }\end{array}$ & 57.7 & 66.1 & 75.3 & 89.7 & 5.4 & $<.001$ \\
\hline
\end{tabular}

nificant differences among the other four groups (ps $>.05$ ). Thus, while there may be a slight nonsignificant trend for nicotine to prolong avoidance responding in extinction, the only significant difference is at the extremely high dose $(.8 \mathrm{mg} / \mathrm{kg})$ in which the drug is physically debilitating and results in cessation of responding. Tests using the Moses extreme reaction tests for two groups at a time also yielded ps $>.10$ for number of extinction responses (except, obviously, for the $.8 \mathrm{mg} / \mathrm{kg}$ group).

\section{DISCUSSION}

Normally classified as a minor stimulant, nicotine has been known to increase or diminish learning and performance in animals, depending on nicotine dosage, animal species, and behavioral situations employed (Domino, 1965; McGaugh \& Petronovich, 1965), and frequently has little behavioral effect (Domino, 1965). Domino (1967) showed that low doses of nicotine tend to retard extinction of a pole-jumping avoidance response. Thus, the behavioral effects observed in our study are consistent with previous research.

Grupp (1981; Grupp \& Stewart, 1983) has shown that intravenous infusion of ethanol can be used much as a shock unconditioned stimulus in producing acquisition of an active or passive avoidance response. The findings of Grupp and the observations of others that selfadministration of ethanol is often not readily obtained strengthen the view that, at least with ethanol in rats, ethanol administration is aversive, and avoidance-extinction effects (e.g., Baum, 1969) can be interpreted in terms of compounding of aversiveness. Apparently, nicotine administration is far less aversive than administration of ethanol because nicotine's effects to prolong avoidance extinction are smaller than those of ethanol.

Another possible interpretation of the drug results outlined in the introduction of this paper is that a drug can depress the inhibitory process which ordinarily results in cessation of responding in extinction. This interpretation is in line with the Hullian notion that response extinction is attributable to reactive inhibition (i.e., occurrence of the response without the reinforcer builds up a fatigue-like inhibitory process) leading to conditioned inhibition, in which resting or doing nothing is reinforced by reduction in this reactive inhibition (reviewed by Tarpy, 1975, p. 148). The results of this study thus can be interpreted as suggesting that nicotine has fewer antiinhibitory properties than ethanol (Baum, 1969) or chlordiazepoxide and diazepam (Ziskind, Amit, \& Baum, 1974).

\section{REFERENCES}

BAUM, M. (1965). An automated apparatus for the avoidance training of rats. Psychological Reports, 16, 1205-1211.

BaUm, M. (1969). Paradoxical effect of alcohol on the resistance-toextinction of an avoidance response in rats. Journal of Comparative \& Physiological Psychology, 69, 238-240.

BAUM, M. (in press). Animal model for agoraphobia using a safetysignal analysis. Behaviour Research \& Therapy.

Domino, E. D. F. (1965). Some behavioral actions of nicotine. In U. S. Von Euler (Ed.), Tobacco alkaloids and related compounds. New York: Pergamon Press.

Domino, E. D. F. (1967). Electroencephalographic and behavioral arousal effects of small doses of nicotine: A neuropsychopharmacological study. Annals of the New York Academy of Science, 216-244.

GrUPP, L. A. (1981). Ethanol as the negative reinforcer in an active avoidance paradigm. Progress in Neuro-Psychopharmacology, 5, 241-244.

GrUPP, L. A., \& STEWART, R. B. (1983). Active and passive avoidance behavior in rats produced by IV infusions of ethanol. Psychopharmacology, 79, 318-321.

JAFFE, P. G., \& BAUM, M. (1971). Increased resistance-to-extinction of an avoidance response in rats following the administration of hashish resin. Psychopharmacologia, 25, 97-102.

McGaugh, J. L., \& Petronovich, L. F. (1965). Effects of drugs on learning and memory. International Review of Neurobiology, 8 , 139-196.

TARPY, R. M. (1975). Basic principles of learning. Glenview, IL: Scott, Foresman.

ZISKIND, D., AMIT,Z., \& BAUM, M. (1974). Resistance to extinction of an avoidance response in rats following the administration of chlordiazepoxide (Librium) or diazepam (Valium). Psychopharmacologia, 38, 231-238.

ZISKIND, D., BAUM, M., \& AMIT, Z. (1973). Failure of ACTH to influence avoidance extinction in a one-way avoidance situation. Bulletin of the Psychonomic Society, 2, 425-426.

(Manuscript received for publication March 13, 1985). 